\title{
Aldosterone-producing adrenocortical carcinoma: an unusual cause of Conn's syndrome with an ominous clinical course
}

\author{
Teresa M Seccia ${ }^{1}$, Ambrogio Fassina ${ }^{2}$, Gastone G Nussdorfer ${ }^{3}$, \\ Achille C Pessina ${ }^{4}$ and Gian Paolo Rossi ${ }^{4}$
}

\author{
${ }^{1}$ Department of Clinical Methodology and Medical, Surgical Technologies, University of Bari, Piazza G Cesare 11, 70124 Bari, Italy \\ ${ }^{2}$ Department of Oncological Sciences: Section of Pathology, University of Padova, Via Giustiniani 2, 35128 \\ Padova, Italy \\ ${ }^{3}$ Department of Human Anatomy and Physiology (Section of Anatomy), University of Padova, Via Gabelli, 35126 Padova, Italy \\ ${ }^{4}$ Department of Clinical and Experimental Medicine, Clinica Medica 4, University of Padova, Via Giustiniani 2, 35128 Padova, Italy \\ (Requests for offprints should be addressed to G P Rossi; Email: gianpaolo.rossi@unipd.it)
}

\begin{abstract}
Aldosterone-producing adrenocortical carcinoma (APAC) is a rare cause of hypertension often diagnosed late because of paucity of information. Thus, we delineated its clinical course and survival rates based on two cases referred to us that featured diverging clinical courses, and on a scrutiny of the literature since 1955 when the first case of APAC was identified. Data on demography, imaging results, hormonal assessment, histology, and clinical course were extracted independently by the investigators. We included in our database 58 cases, most presenting with Conn's syndrome. Plasma aldosterone levels were on average increased 14-fold; plasma renin activity was suppressed in $55 \%$ of cases. The tumor showed extremely variable size and weight, and no gender or side preference. Metastases were present in $10 \%$ of all cases at initial diagnosis and in an additional $48 \%$ of cases at follow-up. Median survival was 546 days (95\% confidence interval (Cl): 240-851); median time to either recurrence or death was 212 days (95\% Cl: 29-395). No clinical or histological signs predicted survival with Cox regression analysis. We concluded that, although an ominous course with a poor survival rate is common, no sign accurately predicts the course of APAC. Thus, molecular studies to identify diagnostic markers of survival are mandatory.
\end{abstract}

Endocrine-Related Cancer (2005) 12 149-159

\section{Introduction}

Hyperaldosteronism (Conn's syndrome), which is usually sustained by an aldosterone producing adeno$\mathrm{ma}$, is the most common cause of curable hypertension (Conn et al. 1964, Lim et al. 1986, Gordon et al. 1994, Rossi et al. 1998). In less than $1 \%$ of patients with Conn's syndrome an aldosterone producing adrenocortical carcinoma (APAC) can be identified (Vallotton 1996, Ganguly 1998). Over the years, numerous criteria have been proposed to clinically recognize APAC (Brode et al. 1962, Weiss et al. 1989, Young et al. 1990, Icard et al. 1992, Schulick \& Brennan 1999, Sasano et al. 2001), but experience has shown that these criteria may be misleading (Rossi et al. 2000).

Adrenocortical tumors are highly prevalent in the general population (Kloos et al. 1995, Mantero et al.
2000); nonetheless, the differentiation between benign and malignant neoplasms is often difficult (Rossi et al. 2000), not only on clinical but even on morphological grounds. Although several criteria have been claimed to allow discrimination between benign and malignant tumors (Lack 1997), including some molecular markers such as the DNA index (Suzuki et al. 1992b, Gicquel \& Le Bouc 1997), the expression of the proliferating cell antigen (Ghnassia et al. 1993), the p53 protein (Reincke et al. 1994), the adrenal 4 binding protein (Sasano et al. 1995), the c-Myc protein (Suzuki et al. 1992a), or the insulin-like growth factor-II gene (Gicquel \& Le Bouc 1997), and the telomerase activity (Mannelli et al. 2000), to date none of them has gained wide acceptance because of their poor accuracy, thus resulting in late diagnosis until metastases occurred. 
We herein report on two cases of APAC with contrasting histological features and divergent clinical course, which suggested a wide heterogeneity of biological behavior and clinical course. Therefore, we created a database with all cases that have been reported since the first description of APAC in 1955 (Foye 1955) that served to delineate the clinical features, natural history, and survival of patients with APAC.

\section{Case reports Case 1}

A 33-year-old woman was referred for evaluation of a right adrenal mass and a 1-month history of mild hypertension. Systolic and diastolic blood pressure ranged between 150 and $160 \mathrm{mmHg}$ and 90 and $95 \mathrm{mmHg}$ respectively. A computed tomography (CT) scan showed a solid, heterogeneous adrenal mass with a maximum diameter of $30 \mathrm{~mm}$. On admission, physical examination was negative; routine laboratory tests, including serum potassium, 24-h urinary catecholamines and low-dose dexamethasone-suppressed plasma cortisol concentrations were all normal. The plasma aldosterone level was elevated both in the sitting (123 pg/ml; normal range: $12-110 \mathrm{pg} / \mathrm{ml})$ and in the upright $(415 \mathrm{pg} / \mathrm{ml}$, normal range: $70-220 \mathrm{pg} / \mathrm{ml})$ position but plasma renin activity was not suppressed. At laparotomy removal of a yellowish, $40 \times 50 \times$ $55 \mathrm{~mm}$ mass was performed; the tumor presented as an ill-defined, large mass with areas of hemorrhage and necrosis. Histopathological examination showed that the tumor was composed of a population of cells with pale, eosinophilic cytoplasm, which were organized in strands and nests, surrounded by collagen (Fig. 1A). Atypical hyperchromatic and pleiomorphic nuclei with coarse chromatin and two or three prominent nucleoli were common (Fig. 1B). Many apoptotic bodies and atypical mitotic figures were present in several high power fields. Invasion of the tumor pseudo-capsule and frequent aspects of microscopic vascular invasion were seen. Expression of p53 and Ki67 was evident at immunohistochemistry. Thus, the histological diagnosis was APAC. Nine years after adrenalectomy, the patient is alive, normotensive, normokalemic and with no signs of recurrence of the primary adrenal tumor.

\section{Case 2}

A 63-year-old woman was initially referred to our institution in June 1998 because of marked weakness and hypokalemia. She reported a history of hypertension, with increased plasma aldosterone levels and a low-normal plasma renin activity. CT scan showed a solid and homogeneous $32 \times 18 \mathrm{~mm}$ adrenal mass and, therefore, a right adrenalectomy was performed. No histological signs of malignancy were noticed and the histological diagnosis was adrenocortical adenoma (Fig. 2A). In February 2000 she was referred again because of marked hypokalemia and uncontrolled hypertension. Physical examination revealed a thoracic ovoid mass of about $75 \mathrm{~mm}$ longitudinal diameter, placed on her 10th left rib. A CT scan showed a normal left adrenal gland, but multiple nodular lesions in the liver, a $60 \mathrm{~mm}$ osteolytic area in the 10th left rib, and multiple vertebral osteolytic areas. The rib lesion was fine-needle aspirated and examined. Cells were atypical and resembled epithelial cells (Fig. 2B). Since their arrangement suggested an adrenocortical origin, the expression of the aldosterone synthase gene was investigated with RT-PCR that showed gene transcripts (Fig. 2C), thus indicating a diagnosis of metastasis from an APAC. Total body scintigraphy after dexamethasone suppression documented uptake of ${ }^{75} \mathrm{Se}$ Met cholesterol by the bone lesions. A re-evaluation of the original surgical specimen from the primary tumor showed no signs of malignancy. The patient died 26 months after removal of the primary adrenal gland tumor, from liver failure and a severe gastric hemorrhage (Rossi et al. 2000).

\section{Methods}

We identified all cases of APAC reported in the literature since 1955, when Foye and Feichtmeier described the first APAC case (Foye 1955), through a Pub Med search and, for older articles published before Pub Med was established, through a meticulous scrutiny of the literature in the Index Medicus. Inclusion criteria were (i) availability of the original paper and (ii) unequivocal diagnosis of APAC. We extracted all relevant available information entailing demography, imaging features, size and weight of the mass, histopathological findings, hormonal data and clinical course. A database was then constructed and used for the analysis.

\section{Statistical analysis}

The average ( \pm S.D.) and median (and range) values were calculated as appropriate. Distribution of categorical variables was compared by $\chi^{2}$ test; significance was set at $P<0.05$. Survival time was considered as the time elapsing from the initial diagnosis of the adrenal 

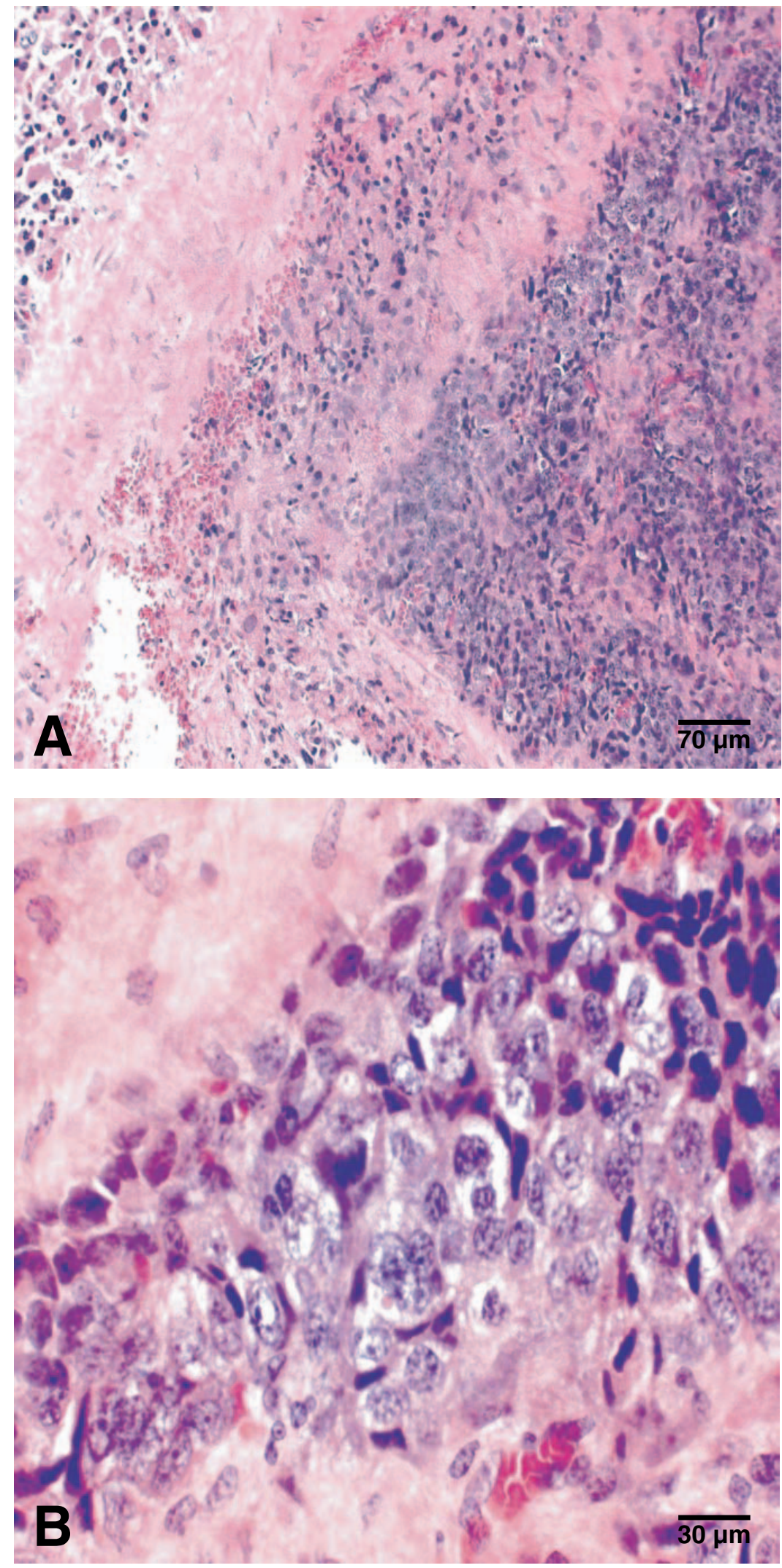

Figure 1 Histopathology of the aldosterone producing adrenocortical carcinoma (APAC) from case 1. (A) The large areas of necrosis and hemorrhage present in the tumor are circumscribed by ill-defined, coarse collagen bands (hematoxylin \& eosin staining; Scale bar: $70 \mu \mathrm{m})$. (B) The nuclei are atypical, hyperchromatic and pleomorphic with coarse chromatin and two or three prominent nucleoli; the cytoplasms are ill defined, eosinophilic and pale (hematoxylin \& eosin staining; Scale bar: $30 \mu \mathrm{m})$. 

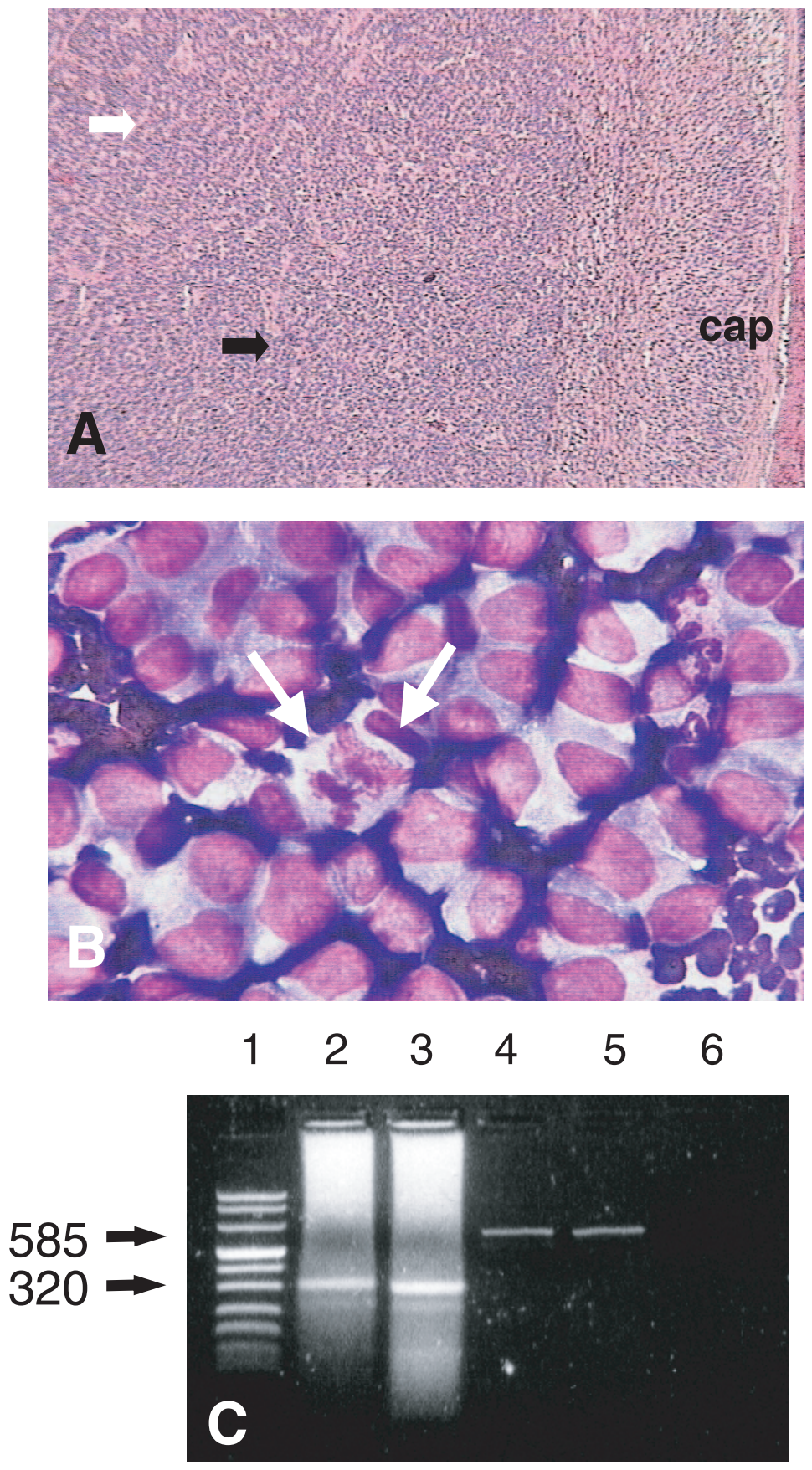

Figure 2 Histopathology of the primary tumor at first identified as adrenocortical adenoma and of the fine-needle aspirated rib lesion that, together with the finding of aldosterone synthase gene expression, suggested malignancy of the primary tumor in case 2. (A) Section of the adrenocortical neoplasia showing two distinct solid patterns of growth: one with anastomosing columns and cords of cells (white arrow) and the other islet-like (black arrow). No cell and nuclear pleomorphism, no trabecular pattern, no capsular or vascular invasion, no mitoses and necrosis were evident. The intact capsula (cap) surrounded a normal adrenocortical tissue (hematoxylin \& eosin staining; Scale bar: $80 \mu \mathrm{m})$. (B) Cytological sample obtained with fine-needle aspirate from an ovoid mass of the left chest wall. Monomorphic cells with abundant cytoplasm are evident. A mitotic figure is present at the center of the field (arrows) (May-GrunwaldGiemsa staining; Scale bar: $20 \mu \mathrm{m})$. (C) Ethidium bromide-stained agarose gels showing cDNA amplified with aldosterone synthase gene-specific primers (lanes 2 and 3) from the sample obtained with fine needle aspirate shown in (B). Amplification of cDNA with primers for the housekeeping gene glyceraldehyde-3-phosphate dehydrogenase (GAPDH) (lanes 4 and 5) and no amplification from no DNA template (lane 6) are also shown. The expected size of the amplification products were $585 \mathrm{bp}$ and $320 \mathrm{bp}$ for aldosterone synthase and GAPDH respectively. mass to censoring at death, or study end. When the date of the initial diagnosis was unavailable, the date of surgery or of first diagnosis of hyperaldosteronism was used instead. Kaplan Meier analysis was used to calculate survival curves and recurrence-free survival. Cox regression analysis was used to evaluate the effects of clinical and histolopathological variables on survival.

\section{Results}

\section{APAC database}

The two cases of APAC herein reported had contrasting histological features and divergent clinical courses: the first, despite showing histopathological features of malignancy, showed a benign clinical course with full recovery that persists after 10 years of follow-up. The 
second, despite a smaller size and no histopathological features of malignancy, which suggested an initial diagnosis of Conn's adenoma, exhibited an ominous clinical course that led to the patient's death in 26 months. Sixty further cases of APAC could be identified in the literature (Foye 1955, Conn et al. 1964, Crane et al. 1965, Santander et al. 1965, Alterman et al. 1969, Brooks et al. 1972, Filipecki et al. 1972, Six et al. 1972, Miyazaki et al. 1973, Salassa et al. 1975, Revach et al. 1977, Boers et al. 1981, Grim et al. 1981, Taylor et al. 1982, Slee et al. 1983, Telner 1983, Arteaga et al. 1984, Greathouse et al. 1984, Levine et al. 1984, Luscher et al. 1984, Sakashita et al. 1984, Stone et al. 1984, Scott et al. 1986, Valentini et al. 1986, Farge et al. 1987, Fraser et al. 1987, Isles et al. 1987, Tenschert et al. 1987, Weiss et al. 1989, Touitou et al. 1992, Barksdale et al. 1993, Boscaro et al. 1995, Weingartner et al. 1995, Sakai et al. 1997, Taylor et al. 1997, Muthusethupathi et al. 1998, Siren et al. 1998, Yamazaki et al. 1998, Deckers et al. 1999, Shen et al. 1999, Parajo et al. 2000, Rossi et al. 2000, Yoshimoto et al. 2000, Dixon \& Bing 2001), four were excluded because either papers were not accessible (Kandrac \& Zikanova 1957, Shah et al. 1975), or the diagnosis of APAC was considered questionable (Salassa et al. 1975). Therefore, 58 cases, including the two described herein, were entered in the database.

\section{Demographic and clinical features}

The large majority of information on demography and biological features, summarized in Table 1, was available in $80 \%$ of the cases. The peak of incidence of APAC was between 40 and 49 years of age (median: 44 years, range: 17-79 years) and a trend towards a preference for women $(57 \%)$ over men $(43 \%)$ and for the right over the left side ( $58 \%$ vs $42 \%$ ) was found.

The hallmarks of Conn's syndrome, e.g. hypertension and hypokalemia, were found in all except three cases, that had hypokalemia but not hypertension (Muthusethupathi et al. 1998, Yamazaki et al. 1998), and in the present case 1 that had hypertension but not hypokalemia.

\section{Tumor size and hormonal features}

Tumor size and weight ranged widely, from 25 to $150 \mathrm{~mm}$ and from 6.3 to $1250 \mathrm{~g}$ (median values $70 \mathrm{~mm}$ and $248 \mathrm{~g}$ respectively). However, pathological staging according to TNM classification was unfeasible because of lack of the necessary information in most reports.

Hyperaldosteronism was found in all cases, but plasma aldosterone levels were reported in 35 cases. Since the range of plasma normal values of aldosterone markedly differed between studies, we calculated the percentage increase from the upper normal value in 34 cases for which both values and normal range were available, and found an average increase of 14-fold. Plasma renin activity was suppressed in $55 \%$ of all cases; however, values were not reported in $27 \%$ of cases.

Most authors measured glucocorticoids and other steroids in plasma. They reported slightly elevated levels of plasma cortisol in 10\% of cases, whereas the plasma levels of dehydro-epiandrosterone sulfate were generally normal. The excretion rate of 17 -hydroxycorticoids and 17-ketosteroids was found to be abnormally high in $8 \%$ and $6 \%$ of cases respectively; however, it was measured in only 28 cases. Other steroid metabolites or

Table 1 Demographic and clinical features. Median and range are given for age, diameter and weight; average and range are given for \% increase of plasma aldosterone levels; means \pm S.E. are given for systolic and diastolic blood pressure, and plasma potassium levels

\begin{tabular}{ll}
\hline Variables & Value \\
\hline Age (years) & $44(17-79)$ \\
Gender (M/F/NA) $(n)$ & $21 / 27 / 10$ \\
Side of tumour (R/L/NA) $(n)$ & $26 / 18 / 14$ \\
Maximum tumor diameter (mm) & $70(25-150)$ \\
Tumor mass weight $(g)$ & $248(6.3-1250)$ \\
Systolic blood pressure (mmHg) & $188 \pm 4$ \\
Diastolic blood pressure $(\mathrm{mmHg})$ & $111 \pm 2$ \\
Hypertension $(n$ of cases; \%) & $55(95 \%)$ \\
Plasma potassium levels (mmEq/l) & $2.30 \pm 0.08$ \\
Hypokalemia (present/absent/NA) $(n, \%)$ & $56(96 \%) / 1(1.7 \%) / 1(1.7 \%)$ \\
Low plasma renin activity (present/absent/NA) $(\mathrm{n}, \%)$ & $32(55 \%) / 10(17 \%) / 16(27 \%)$ \\
$\%$ increase of aldosterone from the upper normal value & $+14(1.1-333)$ \\
Adrenalectomy (performed/not performed/NA) & $52 / 4 / 2$
\end{tabular}

$M$, male; F, female; NA, not available; $R$, right; $L$, left. 
A $\quad$ B
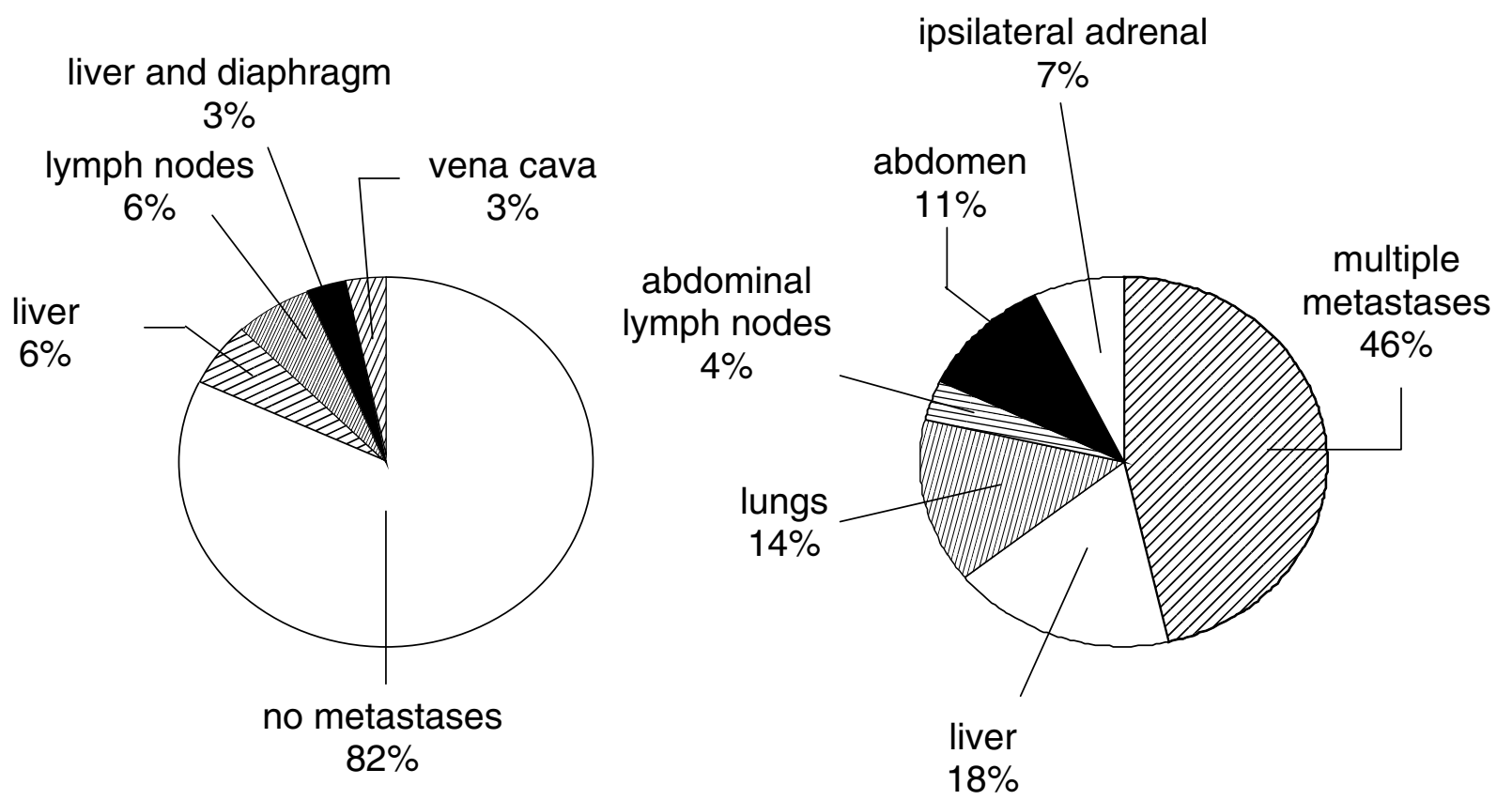

Figure 3 Localization of metastases in APAC. (A) Pie graph shows occurrence of metastases at the time of the initial diagnosis. No metastases were observed in $82 \%$ of cases. In the remaining cases metastases were localized in liver (6\%), lymph nodes $(6 \%)$, vena cava $(3 \%)$, or in liver and diaphragm (3\%). (B) Localization of metastases at the time of the recurrence of the disease. In most cases (46\%) they developed in multiple sites. Single localization occurred in liver, lungs, abdomen, ipsilateral adrenal and abdominal lymph nodes. Values were calculated as percentage of cases developing metastases.

precursors were measured in too few cases to warrant any conclusion.

\section{Imaging characteristics}

Intravenous pyelography, angiography, and/or ultrasonography were used to visualize the mass in 20 cases before CT became available. These tests showed either a highly vascularized tissue or a heterogeneous mass due to the presence of necrotic areas and/or calcifications in $45 \%$ of cases. CT was performed in $38 \%$ of cases, while no information on magnetic resonance (MR) features of APAC is available. One or more CT signs evocative of malignancy, such as heterogeneous density, calcifications, capsular invasion, organ displacement and/or intra-mass hemorrhages, were found in less than half $(46 \%)$ of cases.

\section{Pathology}

Adrenalectomy was performed in $90 \%$ of all cases; two cases were medically treated (Crane et al. 1965, Telner 1983), in two the tumor was detected only at necropsy
(Santander et al. 1965, Alterman et al. 1969), and in another two there was no information on treatment. The macroscopic examination of the surgical specimens revealed calcifications, areas of necrosis and/or hemorrhages and/or invasion of adjacent tissues in $70 \%$ of 28 cases for which information was available. There was no information on occurrence of metastases in $43 \%$ of the 58 cases at the time of the initial diagnosis; in 6 of the 34 that had detailed information on metastases they localized to liver $(6 \%)$, lymph nodes $(6 \%)$, vena cava $(3 \%)$, or to liver and diaphragm $(3 \%)$ (Fig. 3A). Microscopically, at least one of the typical signs of malignancy, such as trabecular pattern, nuclear grade, mitotic rate, atypical mitoses, necrosis, invasion of capsule and/or of venous or sinusoidal structures (Lack 1997), were noticed in 79\% of all cases. Interestingly, in two cases, including our case 2, there were no signs of malignancy (Dixon \& Bing 2001).

\section{Effects of surgery and clinical course}

Information on follow-up after surgery or initial diagnosis was available in only 48 cases, but the length of 

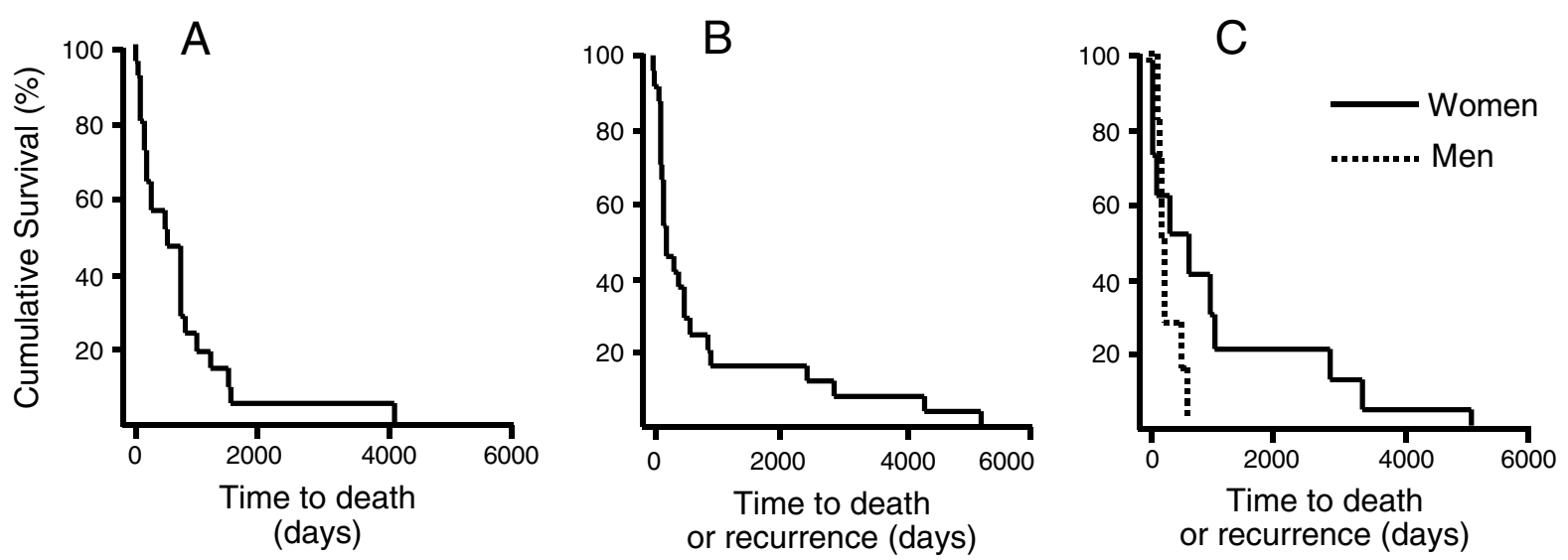

Figure 4 Survival and recurrence-free survival rates in APAC. Kaplan Meier analysis showed that median survival, considered as time elapsing from diagnosis to death or study end, was 546 days (A). The median recurrence-free survival, that was calculated as time elapsing from diagnosis to either recurrence or death, was 212 days (B). Recurrence-free survival according to gender showed a worse trend in men than in women $(C)$, but this did not attain statistical significance. In all three analyses, when the date of initial diagnosis was not specified, the date of surgery or, if this date was also missing, of diagnosis of hyperaldosteronism, were considered instead.

available follow-up ranged widely and was sometimes very short (median value 15 months; range 1-132 months). Adrenalectomy was reported to initially cure both hypokalemia and hypertension in most cases; a mild form of hypertension persisted in $15 \%$ of cases and hypokalemia only in one case. Interestingly, one patient was normotensive after adrenalectomy despite persistent hyperaldosteronism (Muthusethupathi et al. 1998).

Recurrence of the disease was described in $48 \%$ of all cases, while no signs of recurrence were documented in $34 \%$ of patients; in the remaining information was unavailable. The organs involved with metastases (Fig. 3B) included liver (18\%), lung(s) (14\%), abdominal lymph nodes $(4 \%)$, abdomen $(11 \%)$, and ipsilateral adrenal site $(7 \%)$. In $46 \%$ of cases that developed metastases at follow-up multiple sites were involved, very often the liver (10/12), lung(s) (6/12) and kidney (4/12). In one case the site of recurrence was not specified (Conn et al. 1964). The histology of metastatic tissue was provided in only 8 studies. In all but two cases, including our case 2 , cytological features resembled those of the primary tumor, with only a greater degree of nuclear pleiomorphism (Dixon \& Bing 2001). In most patients, metastases were associated with recurrence of hypertension and hypokalemia; however, in one patient liver metastases with no increase in aldosterone or hypokalemia were documented (Dixon \& Bing 2001).

\section{Kaplan Meier and Cox analyses}

At Kaplan Meier analysis the median survival was 546 days (95\% confidence interval (CI): 240-851) (Fig. 4A); a shorter time (212 days) was found when considering time to either recurrence or death $(95 \% \mathrm{CI}$ : $29-395$; Fig. 4B). Cox regression showed that age, hypokalemia, weight, diameter of the adrenal mass, histological signs of malignancy or metastases at the time of diagnosis did not predict survival. A trend towards a worse recurrence-free survival was seen in men compared with women (Fig. 4C), but it did not attain statistical significance.

\section{Discussion}

Adrenocortical carcinomas causing arterial hypertension with an exclusive oversecretion of mineralocorticoids are exceedingly rare, although they might be underreported with ensuing underestimation of their prevalence. Aldosterone overproduction often concurs with that of other steroids, including glucocorticoids, estrogens or androgens, thus leading to Cushing's syndrome, virilization or feminization (Icard et al. 1992, Barzon et al. 1997, Schulick \& Brennan 1999). Moreover, most cases of Conn's syndrome are accounted for by a unilateral adenoma or uni- or bilateral adrenal hyperplasia (Young 1999). Accordingly, the rarity of APAC might explain the lack of 
information on biological behavior, clinical features, natural history, and survival of APAC patients.

Over the past decade in a relatively large series of consecutive cases of Conn's syndrome we observed two cases of APAC, which had contrasting histological features and divergent clinical courses, and differed to some extent also from those previously reported. The first had histological features consistent with a malignant neoplasm, but was long-term cured by adrenalectomy. The second initially showed no histological evidence of malignancy at adrenalectomy and was diagnosed as a Conn's adenoma (Rossi et al. 2000), but 18 months later manifested itself again with Conn's syndrome and a widespread metastatic disorder that was fatal in a few months. In both cases, at CT scan the tumor size was smaller than $40 \mathrm{~mm}$ in diameter and therefore did not have the large size that has been proposed as an indication for adrenalectomy. Thus, it would appear that neither the size at CT scan nor the histological features accurately predict clinical course and outcome in APAC.

We therefore built a database that served to outline the features of this disease based on a search of all published APAC cases. This allowed us to determine that the peak incidence of APAC was in the fourth decade, e.g. similar to that reported for adrenocortical carcinoma (Schulick \& Brennan 1999, Wajchenberg et al. 2000), Conn's adenoma, and bilateral hyperplasia (Melby 1972, Lack 1997). A trend towards a predominance of APAC in women, similar to that reported for adrenocortical carcinoma (Schulick \& Brennan 1999) and aldosterone producing adenoma (APA) (Grant et al. 1984, Lack 1997) was noticed.

In most cases the clinical picture featured the classical signs of Conn's syndrome, e.g. hypertension and hypokalemia. The latter, when marked, was reported to be associated with weakness and diffuse muscular pain, but these signs and symptoms, being common in hyperaldosteronism due to adrenocortical adenoma or hyperplasia, are not helpful in identifying APAC. Moreover, other symptoms, such as fever or weight loss, that are frequent in adrenocortical carcinoma (Pommier \& Brennan 1992, Schulick \& Brennan 1999), were rarely found in APAC.

A large tumor size is usually taken as a presumptive sign of malignancy in clinical practice (Greathouse et al. 1984, Young 1997). In contrast, our present meta-analysis documented that very small tumors can also be malignant, since $9 \%$ of all cases, including our case 2, were smaller than $3 \mathrm{~cm}$ (Greathouse et al. 1984, Weingartner et al. 1995, Deckers et al. 1999, Dixon \& Bing 2001), and developed metastases (Deckers et al. 1999, Rossi et al. 2000, Dixon \& Bing 2001). As regards side, we found a trend towards a predominance of APAC in the right versus the left side that can be at variance with the left side prevalence of adrenocortical carcinomas (Schulick \& Brennan 1999).

Thus, it would appear that the demographic features of the patients, the size and the side of the tumor do not allow unequivocal identification of APAC nor do they predict recurrence after surgery.

The concomitant production of steroids causing a variety of clinical syndromes has been contended to be another criterion that should alert physicians to the presence of APAC. However, production of glucocorticoids or sex steroids was reported only in a few patients and, therefore, it should be acknowledged that there is no solid evidence supporting the usefulness of this criterion.

Of interest, normal values of plasma aldosterone and/or potassium were described in some patients with metastases of histologically confirmed APAC (Brooks et al. 1972, Dixon \& Bing 2001), suggesting that APAC might change their biology over time into poorly differentiated tumors that, while originating metastases, no longer overproduce aldosterone.

\section{CT and pathological findings}

Only $46 \%$ of the 28 cases with CT results showed at least one CT sign of malignancy, but these features were deemed to be non specific and are often seen in other metastatic neoplasms or granulomatous infections (Schulick \& Brennan 1999). Whether the MR features could be more specific remains unsettled, because of the lack of information on this technology in APAC.

As regards histology, at least two well-documented cases (Rossi et al. 2000, Dixon \& Bing 2001) showed that signs of malignancy may be lacking. In our case 2 , the primary neoplasm showed no signs of malignancy and the diagnosis of APAC was retrospectively made when metastases were documented. In striking contrast, our case 1 showed clear signs of malignancy, but exhibited a benign clinical course, thus indicating that histology might be misleading in predicting survival. Recently, attention has been focused on the potential usefulness of molecular and cellular markers, such as PCNA, Ki67 and DNA aneuploidy, for diagnosing adrenocortical carcinoma (Sasano et al. 2001). At present, however, the evidence supporting their usefulness for diagnosing APAC is scant.

\section{Metastases}

Disappointingly enough, the demonstration of metastases at initial diagnosis or follow-up would seem to 
be the only clear-cut criterion for diagnosing APAC. In this meta-analysis metastases were seen in $10 \%$ of all cases at initial diagnosis and in $48 \%$ at follow-up. These rates do not differ considerably from those seen in adrenocortical carcinomas (Icard et al. 1992).

\section{Clinical course}

We used statistical techniques to determine survival curves and to calculate median time to recurrence and death for APAC since there was no information on this important issue. Kaplan Meier analysis showed a median survival of 546 days that is similar to the value of 435 found in a cohort of 105 patient with adrenocortical carcinoma (Luton et al. 1990). We also sought to identify the predictors of survival with Cox analysis and found that neither clinical signs nor histological features of malignancy were accurate predictors of survival.

\section{Perspectives and conclusion}

This study shows that the clinical features of APAC are quite variable, although an ominous clinical course with a poor survival was common. Hence, a high degree of alert for the presence of APAC should be exercised even when all common criteria suggestive of malignancy are lacking. We successfully used a molecular analysis to diagnose metastasis in case 2 and we are currently exploiting the use of DNA microarray technology for gene expression profiling in order to identify gene markers that can unequivocally discriminate carcinomas from adenomas. Given the rarity of APAC an international Register and a tissue bank of documented cases could be a major step for better clarifying the features of this unusual cause of hypertension and for understanding the complexity of its molecular mechanisms.

\section{Acknowledgements}

This study was supported by grants from the Italian Cabinet of University and Scientific Research (MURST) to A C P (9906193152_001/06) and by F.O.R.I.C.A. (The Foundation for Advanced Research In Hypertension and Cardiovascular Diseases) to G P R.

\section{Funding}

The authors declare that there is no conflict of interest that would prejudice the impartiality of this scientific work.

\section{References}

Alterman SL, Dominguez C, Lopez-Gomez A \& Lieber AL 1969 Primary adrenocortical carcinoma causing aldosteronism. Cancer 24 602-609.

Arteaga E, Biglieri EG, Kater CE, Lopez JM \& Schambelan M 1984 Aldosterone-producing adrenocortical carcinoma. Preoperative recognition and course in three cases. Annals of Internal Medicine 101 316-321.

Barksdale SK, Marincola FM \& Jaffe G 1993 Carcinosarcoma of the adrenal cortex presenting with mineralocorticoid excess. American Journal of Surgical Pathology 17 941-945.

Barzon L, Fallo F, Sonino N, Daniele O \& Boscaro M 1997 Adrenocortical carcinoma: experience in 45 patients. Oncology 54 490-496.

Boers GH, Bogman MJ, Debruyne FM, Hoefnagels WH, Kloppenborg PW \& Drayer JI 1981 Hyperaldosteronism due to adrenocortical carcinoma 12 years after surgical removal of an aldosterone-producing adrenocortical adenoma. Netherlands Journal of Medicine 24 185-189.

Boscaro M, Fallo F, Barzon L, Daniele O \& Sonino N 1995 Adrenocortical carcinoma: epidemiology and natural history. Minerva Endocrinologica 20 89-94.

Brode E, Grant JK \& Symington T 1962 A biochemical and pathological investigation of adrenal tissues from patients with Conn's syndrome. Acta Endocrinologica 41 411-431.

Brooks RV, Felix-Davies D, Lee MR \& Robertson PW 1972 Hyperaldosteronism from adrenal carcinoma. British Medical Journal 1 220-221.

Conn JW, Knopf RF \& Nesbit RM 1964 Clinical characteristics of primary aldosteronism from an analysis of 145 cases. American Journal of Surgery 107 159-172.

Crane MG, Harris JJ \& Herber R 1965 Primary aldosteronism due to an adrenal carcinoma. Annals of Internal Medicine 63 494-503.

Deckers S, Derdelinckx L, Col V, Hamels J \& Maiter D 1999 Peritoneal carcinomatosis following laparoscopic resection of an adrenocortical tumor causing primary hyperaldosteronism. Hormone Research 52 97-100.

Dixon AN \& Bing RF 2001 Two cases of adrenocortical carcinoma presenting as Conn's syndrome. Journal of Human Hypertension 15 75-79.

Farge D, Chatellier G, Pagny JY, Jeunemaitre X, Plouin PF \& Corvol P 1987 Isolated clinical syndrome of primary aldosteronism in four patients with adrenocortical carcinoma. American Journal of Medicine 83 635-640.

Filipecki S, Feltynowski T, Poplawska W, Lapinska K, Krus S, Wocial B \& Januszewicz W 1972 Carcinoma of the adrenal cortex with hyperaldosteronism. Journal of Clinical Endocrinology and Metabolism 35 225-229.

Foye LVJ 1955 Adrenal cortical carcinoma producing solely mineralocorticoid effect. American Journal of Medicine 19 966-975.

Fraser AG, Croxson MS, Espiner EA \& Synek B 1987 Adrenocortical carcinoma presenting as primary aldosteronism in a young man. Australia and New Zealand Journal of Medicine 17 60-62. 
Ganguly A 1998 Primary aldosteronism. New England Journal of Medicine 339 1828-1834.

Ghnassia JP, Wagner M, Gasser B \& Walter PR 1993 Adrenal cortical tumors. Prognostic evaluation of a series of 12 cases using anti-PCNA antibodies. Annals of Pathology 13 312-316.

Gicquel C \& Le Bouc Y 1997 Molecular markers for malignancy in adrenocortical tumors. Hormone Research 47 269-272.

Gordon RD, Stowasser M, Tunny TJ, Klemm SA \& Rutherford JC 1994 High incidence of primary aldosteronism in 199 patients referred with hypertension. Clinical Experimental Pharmacology and Physiology 21 315-318.

Grant CS, Carpenter P, van Heerden JA \& Hamberger B 1984 Primary aldosteronism. Clinical management. Archives of Surgery 119 585-590.

Greathouse DJ, McDermott MT, Kidd GS \& Hofeldt FD 1984 Pure primary hyperaldosteronism due to adrenal cortical carcinoma. American Journal of Medicine $\mathbf{7 6}$ 1132-1136.

Grim CE, Ganguly A, Yum MN, Donohue JP \& Weinberger MH 1981 Hyperaldosteronism due to unsuspected adrenal carcinoma: discovery during investigation of hypertension in a young woman. Journal of Urology 126 783-786.

Icard P, Chapuis Y, Andreassian B, Bernard A \& Proye C 1992 Adrenocortical carcinoma in surgically treated patients: a retrospective study on 156 cases by the French Association of Endocrine Surgery. Surgery 112 972-979.

Isles CG, MacDougall IC, Lever AF \& Fraser R 1987 Hypermineralocorticoidism due to adrenal carcinoma: plasma corticosteroids and their response to ACTH and angiotensin II. Clinical Endocrinology 26 239-251.

Kandrac MS \& Zikanova OM 1957 Aldosterone and corticosteroids in a patient suffering from primary aldosteronism and carcinoma of the adrenal cortex. $S b$ Lekarsky 59 283-288.

Kloos RT, Gross MD, Francis IR, Korobkin M \& Shapiro B 1995 Incidentally discovered adrenal masses. Endocrine Reviews 16 460-484.

Lack EE 1997 Adrenal cortical carcinoma. In Tumors of the Adrenal Gland and Extradrenal Paraganglia, pp. 123-147. Ed. EE Lack. Washington: Armed Forces Institute of Pathology.

Levine DS, Fischer DG \& Forman BH 1984 Isolated production of aldosterone by a malignant adrenal carcinoma. Yale Journal of Biology and Medicine $\mathbf{5 7}$ 833-841.

Lim RC, Nakayama DK, Biglieri EG, Schambelan M \& Hunt TK 1986 Primary aldosteronism: changing concepts in diagnosis and management. American Journal of Surgery 152 116-121.

Luscher T, Tenschert W, Salvetti A, Pedrinelli R, Maurer R, Turini F, Maltinti G, Vetter H \& Vetter W 1984 Primary aldosteronism due to adrenal carcinomas. Klin Wochenschr 62 470-477.
Luton JP, Cerdas S, Billaud L, Thomas G, Guilhaume B, Bertagna X, Laudat MH, Louvel A, Chapuis Y \& Blondeau P 1990 Clinical features of adrenocortical carcinoma, prognostic factors, and the effect of mitotane therapy. New England Journal of Medicine 322 1195-1201.

Mannelli M, Gelmini S, Arnaldi G, Becherini L, Bemporad D, Crescioli C, Pazzagli M, Mantero F, Serio M \& Orlando C 2000 Telomerase activity is significantly enhanced in malignant adrenocortical tumors in comparison to benign adrenocortical adenomas. Journal of Clinical Endocrinology and Metabolism 85 468-470.

Mantero F, Terzolo M, Arnaldi G, Osella G, Masini AM, Ali A, Giovagnetti M, Opocher G \& Angeli A 2000 A survey on adrenal incidentaloma in Italy. Study Group on Adrenal Tumors of the Italian Society of Endocrinology. Journal of Clinical Endocrinology and Metabolism $\mathbf{8 5}$ 637-644.

Melby JC 1972 Identifying the adrenal lesion in primary aldosteronism. Annals of Internal Medicine 76 1039-1041.

Miyazaki G, Sasano N, Torikai T \& Fukuchi S 1973

Adrenocortical carcinoma with an isolated mineralocorticoid excess and recurrency fourteen years after removal of the tumor. Tohoku Journal of Experimental Medicine 109 365-375.

Muthusethupathi MA, Vimala A, Jayakumar M \& Rajendran S 1998 Normotensive primary aldosteronism due to adrenocortical carcinoma. Nephron 79 247-248.

Parajo A, Firvida JL, Otero E, Garcia M \& Montero M 2000 Isolated primary hyperaldosteronism caused by adrenocortical carcinoma. Archivos Espanoles de Urologia 53 931-934.

Pommier RF \& Brennan MF 1992 An eleven-year experience with adrenocortical carcinoma. Surgery 112 963-970.

Reincke M, Karl M, Travis WH, Mastorakos G, Allolio B, Linehan HM \& Chrousos GP 1994 p53 mutations in human adrenocortical neoplasms: immunohistochemical and molecular studies. Journal of Clinical Endocrinology and Metabolism 78 790-794.

Revach M, Shilo S, Cabili S, Rubenstein Z \& Selzer G 1977 Hyperaldosteronism caused by adrenal cortical carcinoma. Israel Journal of Medical Sciences $\mathbf{1 3}$ 1123-1128.

Rossi GP, Rossi E, Pavan E, Rosati N, Zecchel R, Semplicini A, Perazzoli F \& Pessina AC 1998 Screening for primary aldosteronism with a logistic multivariate discriminant analysis. Clinical Endocrinology 49 713-723.

Rossi GP, Vendraminelli R, Cesari M \& Pessina AC 2000 A thoracic mass with hypertension and hypokalaemia. Lancet 3561570.

Sakai N, Yamada T, Asao T \& Murayama T 1997 Aldosterone-producing adrenocortical carcinoma metastases found seven years after adrenalectomy. International Journal of Urology 4 79-82.

Sakashita S, Kashiwagi A, Maru A, Ito Y, Chiba H, Kurosawa S, Inoue K \& Koyanagi T 1984 Primary aldosteronism due to adrenal cortical carcinoma. Journal of Urology 132 959-961. 
Salassa TM, Weeks RE, Northcutt RC \& Carney JA 1975 Primary aldosteronism and malignant adrenocortical neoplasia. Transactions of the American Clinical Climatological Association 86 163-172.

Santander R, Gonzalez A \& Suarez JA 1965 Case of probable mineralocorticoid excess without hypercortisolism due to a carcinoma of the adrenal cortex. Journal of Clinical Endocrinology and Metabolism 25 1429-1435.

Sasano H, Shizawa S, Suzuki T, Takayama K, Fukaya T, Morohashi K \& Nagura H 1995 Transcription factor adrenal 4 binding protein as a marker of adrenocortical malignancy. Human Pathology 26 1154-1156.

Sasano H, Suzuki T \& Moriya T 2001 Discerning malignancy in resected adrenocortical neoplasms. Endocrine Pathology 12 397-406.

Schulick RD \& Brennan MF 1999 Adrenocortical carcinoma. World Journal of Urology 17 26-34.

Scott HWJ, Sussman CR, Page DL, Thompson NW, Gross MD \& Lloyd R 1986 Primary hyperaldosteronism caused by adrenocortical carcinoma. World Journal of Surgery $\mathbf{1 0}$ 646-653.

Shah S, McReynolds CR, Decker DD \& Hoofer WD 1975 Aldosteronism-hypokalemia. Adenocarcinoma of adrenal gland. Journal of the Kansas Medical Society 76 277-278.

Shen WT, Lim RC, Siperstein AE, Clark OH, Schecter WP, Hunt TK, Horn JK \& Duh QY 1999 Laparoscopic vs open adrenalectomy for the treatment of primary hyperaldosteronism. Archives of Surgery 134 628-631.

Siren J, Valimaki M, Huikuri K, Sivula A, Voutilainen P \& Haapiainen R 1998 Adrenalectomy for primary aldosteronism: long-term follow-up study in 29 patients. World Journal of Surgery 22 418-421.

Six R, Leclercq R \& Noeninckx F 1972

Hypermineralocorticoidism: the sole clinical manifestation of an adrenal cortical carcinoma. Acta Clinical Belgica 27 426-434.

Slee PH, Schaberg A \& van Brummelen P 1983 Carcinoma of the adrenal cortex causing primary hyperaldosteronism. A case report and review of the literature. Cancer $\mathbf{5 1}$ 2341-2345.

Stone NN, Janoski A, Muakkassa W \& Shpritz L 1984 Mineralocorticoid excess secondary to adrenal cortical carcinoma. Journal of Urology 132 962-965.

Suzuki T, Sasano H, Nisikawa T, Rhame J, Wilkinson DS \& Nagura H 1992a Discerning malignancy in human adrenocortical neoplasms: utility of DNA flow cytometry and immunohistochemistry. Modern Pathology $5224-231$.

Suzuki T, Sasano H, Nisikawa T, Rhame J, Wilkinson DS \& Nagura H $1992 b$ Discerning malignancy in human adrenocortical neoplasms: utility of DNA flow cytometry and immunohistochemistry. Modern Pathology $5224-231$.

Taylor HC, Douglas JG, Berg GJ \& Bravo EL 1982 Primary aldosteronism caused by adrenal cortical carcinoma. Endocrinologia Japonica 29 701-708.
Taylor W, Carroll D \& Bethwaite P 1997 Adrenal carcinoma presenting as Conn's syndrome. Australia and New Zealand Journal of Medicine 27 201-202.

Telner AH 1983 Adrenal cortical carcinoma: an unusual cause of hyperaldosteronism. Canadian Medical Association Journal 129 731-732.

Tenschert W, Maurer R, Vetter H \& Vetter W 1987 Primary aldosteronism by carcinoma of the adrenal cortex. Klinische Wochenschrift $\mathbf{6 5}$ 428-432.

Touitou Y, Boissonnas A, Bogdan A \& Auzeby A 1992 Concurrent adrenocortical carcinoma and Conn's adenoma in a man with primary hyperaldosteronism. In vivo and in vitro studies. Acta Endocrinologica 127 189-192.

Valentini F, Pavoncello S, Di Paolo A \& Minucci S 1986 Primary hyperaldosteronism due to adrenocortical carcinoma. A clinical case report. Minerva Medica 77 1813-1818.

Vallotton MB 1996 Primary aldosteronism. Part I. Diagnosis of primary hyperaldosteronism. Clinical Endocrinology $\mathbf{4 5}$ 47-52.

Wajchenberg BL, Albergaria Pereira MA, Medonca BB, Latronico AC, Campos CP, Alves VA, Zerbini MC, Liberman B, Carlos GG \& Kirschner MA 2000 Adrenocortical carcinoma: clinical and laboratory observations. Cancer 88 711-736.

Weingartner K, Gerharz EW, Bittinger A, Rosai J, Leppek R \& Riedmiller H 1995 Isolated clinical syndrome of primary aldosteronism in a patient with adrenocortical carcinoma. Case report and review of the literature. Urologica Internationalis 55 232-235.

Weiss LM, Medeiros LJ \& Vickery AL Jr 1989 Pathologic features of prognostic significance in adrenocortical carcinoma. American Journal of Surgery and Pathology 13 202-206.

Yamazaki H, Abe Y, Katoh Y, Sawa N, Ohnishi Y, Tanaka Y, Sasano H, Oshika Y, Tokunaga T, Kijima H, Tamaoki N, Nakamura M \& Ueyama Y 1998 Establishment of an adrenocortical carcinoma xenograft with normotensive hyperaldosteronism in vivo. Acta Pathologica, Microbiologica et Immunologica Scandinavica 106 1056-1060.

Yoshimoto T, Naruse M, Ito Y, Naruse K, Ueda T, Tanabe A, Harada S, Nishikawa T, Sasano H, Obara T \& Demura H 2000 Adrenocortical carcinoma manifesting pure primary aldosteronism: a case report and analysis of steroidogenic enzymes. Journal of Endocrinological Investigation 23 112-117.

Young WF Jr 1997 Pheochromocytoma and primary aldosteronism. Cancer Treatment Research 89 239-261.

Young WF Jr 1999 Primary aldosteronism: a common and curable form of hypertension. Cardiology in Review 7 207-214.

Young WF Jr, Hogan MJ, Klee GG, Grant CS \& van Heerden JA 1990 Primary aldosteronism: diagnosis and treatment. Mayo Clinic Proceedings 65 96-110. 
